\title{
Chemiluminescent Ozone Instrument for Aircraft Observation
}

\author{
By Y. Kondo, H. Kojima, N. Toriyama, Y. Morita, M. Takagi \\ Research Institute of Atmospherics, Nagoya University, Toyokawa, Aichi, Japan \\ and \\ W. A. Matthews \\ Physics and Engineering Laboratory, Lauder, Department of Scientific and Industrial Research, \\ Lauder, Central Otago, New Zealand \\ (Manuscript received 18 May 1987, in revised form 10 August 1987)
}

\begin{abstract}
An ethylene-ozone chemiluminescent instrument has been modified so that it can control the sample and ethylene flow rates irrespective of the ambient pressure and temperature. Through detailed laboratory tests the following characteristics have been found.

(1) The sensitivity of the instrument is highly dependent on the sample mass flow rate as expected from the chemiluminescent reaction scheme. (2) The change in sensitivity as a function of the ethylene mass flow rate is much less. (3) The error associated with the stability of the zero level and the standard deviation from a linear relationship is less than 1 ppbv. (4) The change in the sensitivity for pressures between 1000 and $500 \mathrm{mb}$ is insignificant. A larger reduction in sensitivity at lower pressures necessitates corrections based on the calibration curve obtained. It amounts to about $10 \%$ at $400 \mathrm{mb}$ under optimum flow conditions.

Aircraft observations of ozone up to the altitude of $6 \mathrm{~km}$ have been made. The flow control system has proved to maintain the flow rates constant to within $3 \%$ on board the aircraft. Ozone mixing ratios obtained by this experiment are also reported.
\end{abstract}

\section{Introduction}

For the measurements of atmospheric ozone at the ground, commercial UV photometers and chemiluminescent ozone instruments are commonly used. However these instruments usually cannot be used for aircraft observations without some design changes due to different environmental conditions. For the measurement of ozone on board an aircraft by modified commercial UV and chemiluminescent instruments, Routhier et al. (1980) adopted a system which involved a pressure regulation of air sampled. Gregory et al. (1983a, b, 1984) also modified a commercial chemiluminescent ozone instrument and used it to make aircraft measurements. One of the most important features of the latter (c) 1987, Meteorological Society of Japan chemiluminescent instrument is that the sensitivity of the instrument in terms of ozone mixing ratio is almost independent of the ambient pressure, at least down to about $650 \mathrm{mb}$. The chemiluminescent technique that compensates for the pressure changes can be considered as one of the promising methods for the accurate determination of the ozone concentration in the free troposphere. However, for any extended use of this type of instrument and for further improvement in its precision, more detailed investigations of the characteristics of the instrument are necessary. Therefore, as a first step, we have also modified a commercial ozone instrument and performed tests with it in the laboratory and we have also made aircraft observations with it. This paper gives a description of these laboratory and field tests. 


\section{Ozone instrument}

The principle of the measurement of the chemiluminescent ozone instrument is based on the chemiluminescent reactions between ozone and ethylene (Finlayson et al., 1972; Aimedieu and Barat, 1981; Mehrabzadeh et al., 1983; O'Brien et al., 1983). In the reaction chamber, ethylene is mixed with sampled ambient air which contains ozone. The chemiluminescence is measured with a photomultiplier tube (PMT) and the magnitude of the PMT signal is proportional to the amount of ozone in the chamber provided there is excess of ethylene as will be shown later. The spectral intensity of the chemiluminescence peaks at about $430 \mathrm{~nm}$ (Finlayson et al., 1972). In a similar way to Gregory et al. (1983a), we have modified a commercial chemiluminescent ozone instrument (Monitor Labs Inc., Model 8410). The PMT used is Hamamatsu R-268, which has a maximum sensitivity at 420 $\mathrm{nm}$. The schematic diagram of the modified instrument is shown in Figure 1. The major modifications are as follows.

1) Regulation of the ethylene flow by a mass flow controller (STEC, SEC-421 MKII).

2) Regulation of the sum of the sample and ethylene mass flow rates by a combination of a mass flow sensor (Ueshima-Brooks, Type 5810) and a servo controlled needle valve (UeshimaBrooks, Type 5835).

3) Adoption of an $A C$ driven pump with pumping capability sufficient to enable measurements down to $250 \mathrm{mb}$ with a power consump-

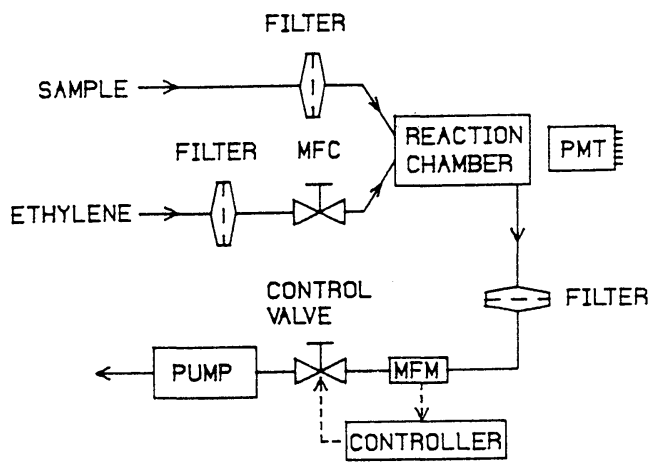

Fig. 1. Schematic diagram of the chemiluminescent ozone instrument. Flow elements are designated as MFC (mass flow controller) and MFM (mass flow meter). tion of about 30 watts (Nitoh Koki Co., VP0660).

In order to remove aerosols in the sample air with diameters larger than $0.3 \mu \mathrm{m}$, a Teflon (TFE) filter (Sumitomo Electric, AF07P) is mounted at the inlet. Teflon (PFA) tubes with internal diameters of 4.4 and $1.6 \mathrm{~mm}$ have been used for plumbing the instrument and for various laboratory tests described below.

\section{Laboratory tests}

The reaction mechanism for the chemiluminescence is as follows,

$$
\begin{array}{ll}
\mathrm{O}_{3}+\mathrm{C}_{2} \mathrm{H}_{4} \longrightarrow \mathrm{HCHO}^{*}+\mathrm{CH}_{2} \mathrm{O}_{2} ; & k_{1} \\
\mathrm{O}_{3}+\mathrm{C}_{2} \mathrm{H}_{4} \longrightarrow \mathrm{HCHO}+\mathrm{CH}_{2} \mathrm{O}_{2} ; & k_{2} \\
\mathrm{HCHO}^{*} \longrightarrow \mathrm{HCHO}+h \nu ; & k_{3} \\
\mathrm{HCHO}^{*}+M \longrightarrow \mathrm{HCHO}+M ; & k_{4}
\end{array}
$$

where $k_{i}$ represents the respective reaction rate coefficient and $M$ stands for any molecule. The total emission rate in the reaction chamber can be expressed as follows (O'Brien et al., 1983; Gregory et al., 1983b).

$$
\begin{aligned}
I= & \frac{k_{1}}{k_{1}+k_{2}} \frac{k_{3}}{k_{3}+k_{4}[M]} f_{s} X \\
& \times\left\{1-\exp \left(-\frac{\left(k_{1}+k_{2}\right) A(1-A)[M]^{2} V}{f_{s}}\right\}\right.
\end{aligned}
$$

where

$$
A=\frac{\left[\mathrm{C}_{2} \mathrm{H}_{4}\right]}{[M]}=\frac{\left[\mathrm{C}_{2} \mathrm{H}_{4}\right]}{[\mathrm{Air}]+\left[\mathrm{C}_{2} \mathrm{H}_{4}\right]} .
$$

$f_{s}$ (molecules $\left.\mathrm{s}^{-1}\right), X$, and $V\left(\mathrm{~cm}^{-3}\right)$ denote the mass flow rate of the sample air, ozone mixing ratio, and the volume of the reaction chamber respectively. The brackets denote the concentration of the assigned species in the reaction chamber. For our instrument $V=16.1 \mathrm{~cm}^{3}$. The reaction rate coefficients are reported as $k_{1}+k_{2}=$ $1.9 \times 10^{-18} \mathrm{~cm}^{3} \mathrm{~s}^{-1}$ (Japar et al., 1974), $k_{1}=$ $3.8 \times 10^{-27} \mathrm{~cm}^{3} \mathrm{~s}^{-1}$ (O'Brien et al., 1983), and $k_{4} / k_{3}=2.8 \times 10^{20} \mathrm{~cm}^{-3}$ (O'Brien et al., 1983). Equation (1) gives the dependence of the emission rate on the sample and ethylene flow rates, temperature, and pressure $([M])$. It should also 
be noted that if these factors are kept constant, I is proportional to ozone mixing ratio. The output signal from the PMT is given by

$$
S=C\left(f_{s}, f_{e}, P\right) I
$$

where $f_{e}$ and $P$ are the ethylene mass flow rate and the pressure in the reaction chamber respectively. Here $C$ is a factor depending on the sensitivity of the $P M T$ and the spatial distribution of the emission in the chamber. As the light gathering efficiency of the $P M T$ decreases with the distance the PMT is from the emitting region, $C$ can be considered to be a function of $f_{s}, f_{e}$, and $P$. Laboratory tests of the response of the instrument to these parameters should provide the necessary information to understand the physical and chemical characteristics of the instrument.

i) Flow rate dependence

A calculation using the rate coefficients already cited shows that for sample mass flow rates between 100 and $500 \mathrm{STP} \mathrm{cm}^{3} / \mathrm{min}$ and for ethylene mass flow rates larger than 20 STP $\mathrm{cm}^{3} /$ min, the exponential term in equation (1) is much smaller than unity. Here it should be noted that $f_{s}$ given in the unit of STP $\mathrm{cm}^{3} /$ min needs to be converted to that in the unit of molecules $\mathrm{s}^{-1}$ in calculating I from equation (1). Under these conditions, equation (1) can be simplified, to a good approximation, as follows

$$
I=\frac{k_{1}}{k_{1}+k_{2}} \frac{k_{3}}{k_{3}+k_{4}[M]} f_{s} X .
$$

I increases linearly with $f_{S}$ and does not depend on the ethylene mass flow rate. The dependence of the chemiluminescent signal $S$ on the sample and ethylene mass flow rates has been measured for a constant ozone mixing ratio of $118 \mathrm{ppbv}$ at 1 atmosphere and is shown in Figures 2(a) and (b) respectively. Throughout the laboratory tests, a UV ozone photometer equipped with an internal UV ozone generator (Thermo Electron Cor., Model 49-100/103) was used to generate ozone from air passed through a charcoal filter and dried with silica gel. The detection limit of the UV photometer is about 2 ppbv. It can be seen from Figure 2(a) that $S$ increases markedly with the sample flow rate. However the rate of increase is not linear, different from the linear in-

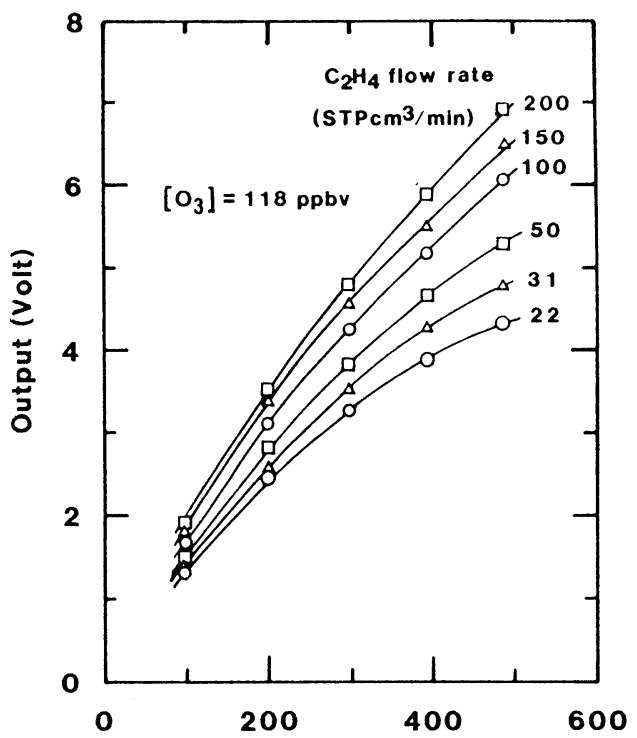

Sample mass flow rate (STP $\left.\mathrm{cm}^{3} / \mathrm{min}\right)$

Fig. 2(a). Measured output signal of the ozone instrument as a function of the sample mass flow rate for various rates of the ethylene mass flow.

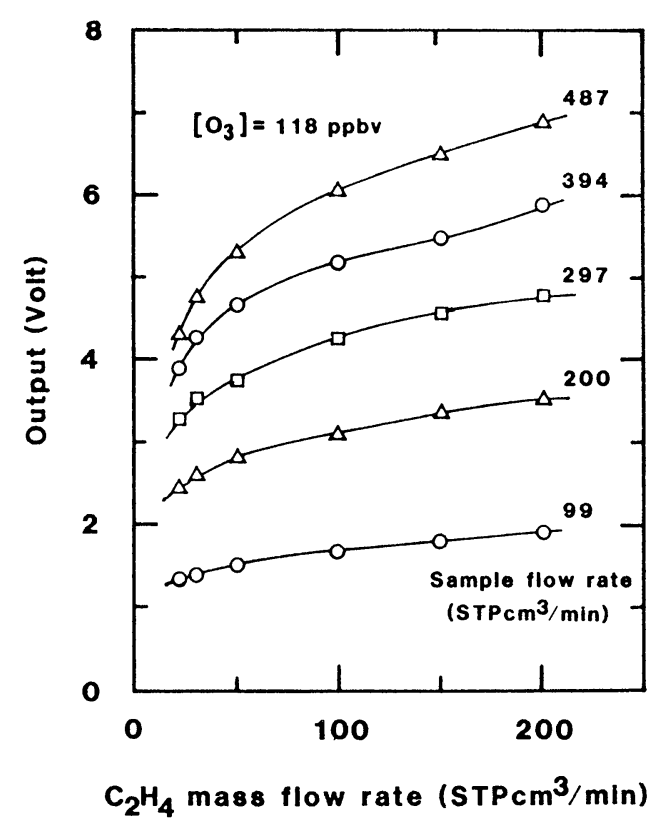

Fig. 2(b). Measured output signal of the instrument as a function of the ethylene mass flow rate for various rates of the sample mass flow.

crease of I expected from equation (3). In addition, as can be seen in Figure 2(b), $S$ increases slowly with ethylene mass flow rate, the largest rate of change in $S$ occurring at small ethylene 
mass flow rates. This is again unexpected from equation (3), which indicates that $I$ is independent of the ethylene mass flow rate.

There are two possible causes for these discrepancies. First, the reaction rate coefficient $k_{1}+k_{2}$ used is too large to make the approximation in (3) valid. Second, the factor $C$ in equation (2) is affected by the chagne in the distribution of the emission in the reaction chamber depending on the flow conditions.

With an increase in the ethylene mass flow rate, the effective emitting region, the volume of which is smaller than that of the reaction chamber, will be closer to the PMT. This will lead to an augmented light gathering efficiency and thus to an increase in the output signal $S$. Calculations of $I$ reducing $k_{1}+k_{2}$ down by a factor of 10 in maximum have shown that the measured dependence of $S$ on the sample and ethylene mass flow rates cannot be well expressed by the exponential term in equation (1). It is therefore likely that it is the dependence of $C$ on the flow conditions that is causing the corresponding change in the output signal $S$.

In actually deriving ozone mixing ratios from recorded $S$ values during observations, calibration curves of the ozone mixing ratio versus $S$ are used. They can be given, through laboratory experiments, as functions of $f_{s}, f_{e}$, and $P$, as is mentioned later. In any case, the ethylene flow as well as the sample flow must be controlled with precision in order to keep constant the sensitivity of the instrument.

\section{ii) Linearity test}

If $f_{s}, f_{e}$, and $P$ are kept constant, $C\left(f_{s}, f_{e}, P\right)$ should be unchanged and therefore, the output signal $S$ is also expected to be linear with ozone mixing ratio (equations (1) and (2)). The value of $S$ as a function of ozone mixing ratio for some combinations of sample and ethylene flow rates have been measured at 1 atmosphere. As an example, the result of the linearity test for the sample and ethylene mass flow rates of 204 and $116 \mathrm{STP} \mathrm{cm}^{3} / \mathrm{min}$ respectively, is shown in Figure 3. From now on in the explanation of this experiment, the value of the sample and the ethylene mass flow rates in the units of STP $\mathrm{cm}^{3} /$ min will be written in abbreviated form which, using the above cases as an example, would be $(204,116)$. The result for $(298,31)$ is also given

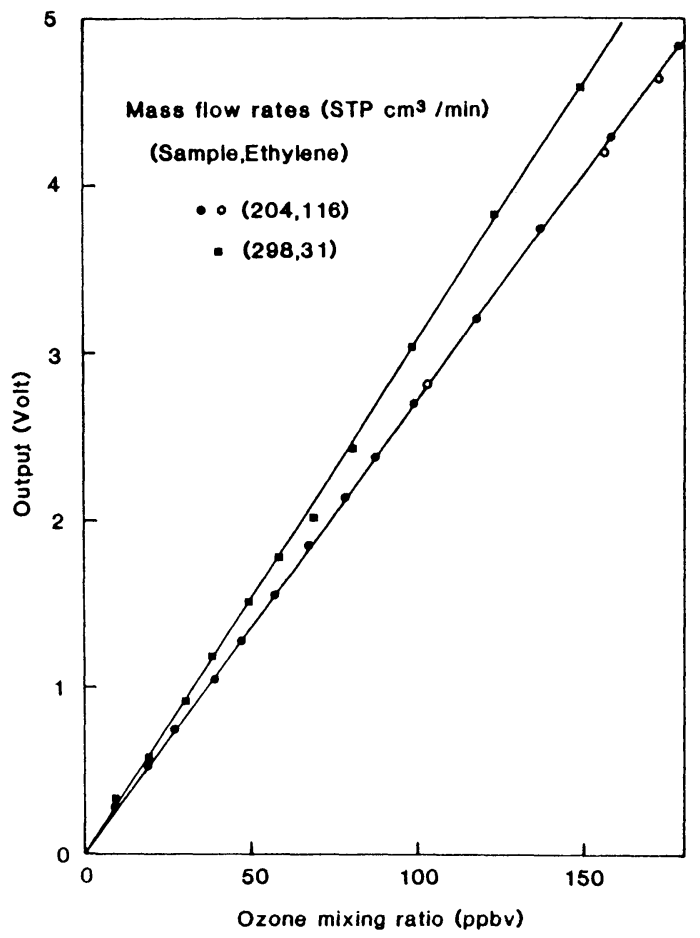

Fig. 3. Output signal of the instrument versus ozone mixing ratio. The value of the sample $\left(f_{s}\right)$ and the ethylene $\left(f_{e}\right)$ mass flow rates in the units of STP $\mathrm{cm}^{3} / \mathrm{min}$ is given in abbreviated form as $\left(f_{s}, f_{e}\right)$. The results obtained one week later are shown as open circles.

in this figure. The standard deviation of the whole data set from the best least square fit is 0.9 ppbv. In this way, the response of $S$ to the ozone mixing ratio has been demonstrated to be linear to within the error of the UV photometer. For the case of $(204,116)$, the results obtained one week later are shown as open circles to demonstrate the good reproducibility of the system. The stability of the sensitivity was tested further as will be discussed later.

\section{iii) Pressure test}

The schematic diagram of the system for the pressure test is shown in Figure 4. The pressure of the sample air is controlled with a servo-controlled needle valve in combination with a calibrated pressure transducer (MKS Baratron). The needle valve is made of stainless steel. The loss of ozone in this valve after it is conditioned with air which contains $200 \pm 100$ ppbv ozone, has been measured to be 4 to $5 \%$ at a pressure of $1000 \mathrm{mb}$. Prior to detailed tests, the sample 


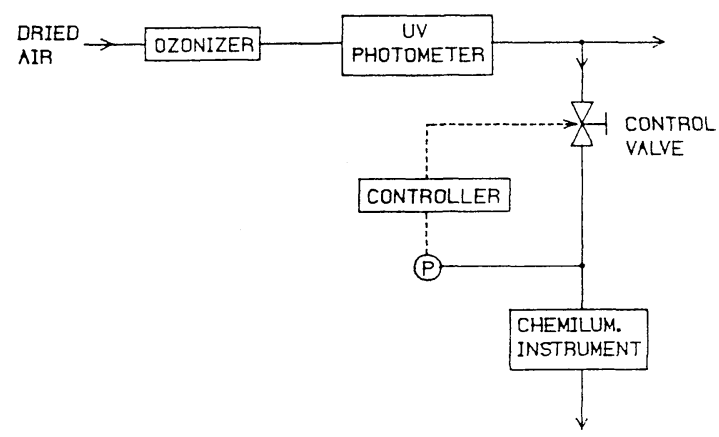

Fig. 4. A laboratory system to test the pressure dependence of the instrument sensitivity. The pressure transducer is designated as $\mathrm{P}$.

mass flow rate $f_{s}$, which is not monitored for normal operation, was checked with a calibrated mass flow meter (Tylan, FM360) over the pressure range of the tests. $f_{s}$ was found to increase by about $3 \%$ with a decrease in pressure from 1000 to $400 \mathrm{mb}$. This was found to be due to the underestimation of the mass flow rate at lower pressures by the sensor used to monitor the total flow rate (Figure 1). This effect does not cause any additional errors in the measurement as the instrument sensitivity is calibrated under these same conditions. In this experiment, the ozone mixing ratio was kept at about 300 ppbv. The ratio of the sensitivity measured at pressures lower than 1 atmosphere to that measured at $1013 \mathrm{mb}$ for five sets of flow rates is shown in Figure 5. The sensitivity at $1000 \mathrm{mb}$ changed by less than $2 \%$ through the experiment suggesting an insignificant error caused by the possible change of the ozone loss rate in the needle valve. As can be seen in this figure, the rate of change in the sensitivity down to $600 \mathrm{mb}$

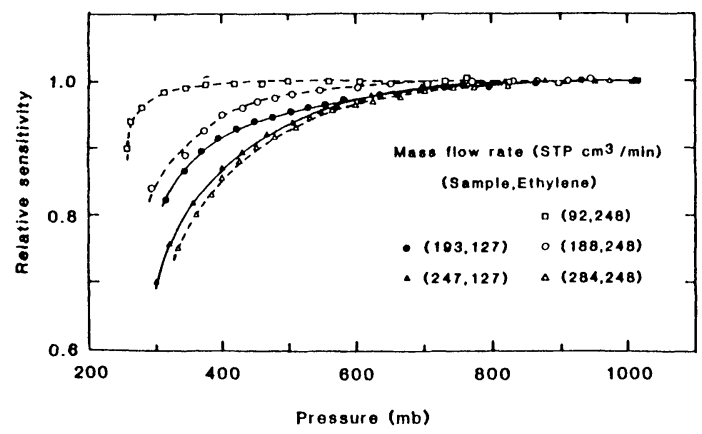

Fig. 5. Relative sensitivity versus pressure normalized at $1013 \mathrm{mb}$ for various combinations of the sample and ethylene mass flow rates. is small. In the case of $(193,127)$, the decrease in the sensitivity is about $5 \%$ and $10 \%$ at 500 and $400 \mathrm{mb}$ respectively. For larger sample flow rates, the sensitivity changes more rapidly. By contrast, with an increase in the ethylene flow rate, the decrease in the sensitivity at low pressures tends to be reduced. For use in aircraft, it would be desirable to operate the instrument with conditions which require a minimum of corrections. The sample flow rate, which partly defines the response of the instrument, and the operational limitation of the ethylene consumption further limit the choice of the sample and ethylene flow rates. We have chosen the flow rates of $(193,127)$ as optimum values for aircraft observations.

\section{iv) The effect of interference}

In the tests that have been discussed so far, the air used was passed through charcoal and silica gel filters as noted above. The volume mixing ratio of the water vapor of the filtered air was monitored to be lower than $1 \%$, typically about $0.7 \%$. The sensitivity of the chemiluminescent instrument has also been measured by using bottled purified air with a water vapor concentration less than 5 ppmv. For ozone mixing ratios between 70 and 160 ppbv, there was no detectable change in the sensitivity when bottled purified air, filtered air, and ambient air with a water vapor mixing ratio of about $1 \%$ were sampled.

It is of interest to further check any possible interferences and the long term stability of the instrument when ambient air is sampled. The chemiluminescent instrument calibrated with the UV photometer, was operated for 6 days in December 1986 sampling outside air together with the UV photometer. The flow condition was chosen to be $(298,31)$. The zero levels of the two instruments were checked repeatedly with bottled purified air. The zero level of the chemiluminescent instrument was found to be stable to within 0.3 ppbv, while that of the UV photometer occasionally shifted by -5 ppbv rather suddendly. Ozone mixing ratios recorded by the two instruments are compared in Figure 6 . The volume mixing ratio of water vapor encountered during this period was between 0.8 and $1.9 \%$. In this figure the data with $\mathrm{H}_{2} \mathrm{O}$ mixing ratios between 0.8 and $1.0 \%$, and those with mixing ratios between 1.0 and $1.9 \%$ are 


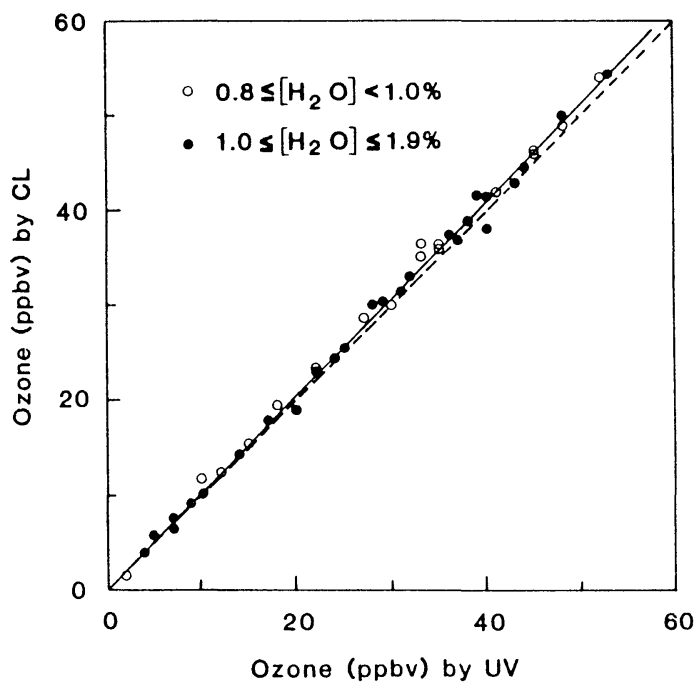

Fig. 6. Comparison of the ozone mixing ratio of the outside air measured with the chemiluminescent instrument and by the UV photometer. Open circles are for the data where the $\mathrm{H}_{2} \mathrm{O}$ mixing ratio was between 0.8 and $1.0 \%$ and the closed circles are for those data where the $\mathrm{H}_{2} \mathrm{O}$ mixing ratio was between 1.0 and $1.9 \%$. The straight line is the linear least square fit for the whole data and the dashed line denotes the $\mathrm{X}=\mathrm{Y}$ relation.

depicted as open and closed circles respectively. The least square linear fit to the whole data set is given by

$$
Y=1.02 X+0.16(\mathrm{ppbv})
$$

where $X$ and $Y$ denote the ozone mixing ratio in ppbv obtained by $U V$ and chemiluminescent methods respectively. The standard deviation of the whole data from the best least square fit is 0.90 ppbv. Considering that the detection limit of the $U V$ photometer is about 2 ppbv, it can be said that there is no detectable interference by water vapor for concentrations between 0.8 and $2 \%$. In addition, these results assure us of the long term stability of the chemiluminescent instrument.

\section{Precision of the measurement}

As far as the present work is concerned, the calibration of the absolute sensitivity depends entirely on the commercial $U V$ photometer, of which the sensitivity is factory set. The $U V$ photometer used for the present experiment has been intercompared with another commerical
$U V$ photometer (Dasibi, Model $1003 \mathrm{AH}$ ) of which the sensitivity has also been factory set against a standard instrument. The two $U V$ photometers agreed to within $3 \%$ for ozone concentrations between 50 and $150 \mathrm{ppbv}$. This would give a measure for the absolute accuracy of the calibration of the chemiluinescent instrument. To further improve the accuracy, the photometer and the chemiluminescent instrument need to be calibrated by intercomparison with more reliable standards or ozone sources. The detection limit is determined by the zero drift and the random fluctuation of the output signal. It is estimated to be about $0.5 \mathrm{ppbv}$ from repeated tests with purified air. At ozone concentrations below $10 \mathrm{ppbv}$, the chemiluminescent instrument appears to be superior to the $U V$ photometer, whose zero level occasionally drifted by 5 ppbv rather suddenly during the 6 days operation.

The tests described above were performed in the laboratory where the temperature ranged between 15 and $30^{\circ} \mathrm{C}$. Under these conditions, the change in the sensitivity with temperature did not exceed $5 \%$.

\section{Aircraft observation}

Aircraft observations of ozone with the chemiluminescent instrument were made on December 16 and 17, 1985 at latitudes between 28 and $38^{\circ} \mathrm{N}$ up to an altitude of $6 \mathrm{~km}$. The observations were made mostly over the sea near Japan along the meridian of about $140^{\circ} \mathrm{E}$. The instrument was operated at the flow rates of $(193,127)$ as already noted. The air intake system is described in Kondo et al. (1987). The air was sampled through a $3.4 \mathrm{~m}$ long Teflon (PFA) tube with an inner diameter of $4.4 \mathrm{~mm}$. The total volume of the sample tube and the reaction chamber was $68 \mathrm{~cm}^{3}$. The residence time of the sample air in this volume is about 20 and $10 \mathrm{~s}$ at the pressures of 1000 and $500 \mathrm{mb}$ respectively. The temperature of the sample air was monitored to be between 10 and $30^{\circ} \mathrm{C}$, depending on the temperature in the cabin of the aircraft. It has been found from laboratory tests that the output signal of the instrument becomes stable 10 minutes after it has been powered up. The output signal for ozone was digitized by a 12-bit AD converter and recorded every $10 \mathrm{~s}$ with a micro- 


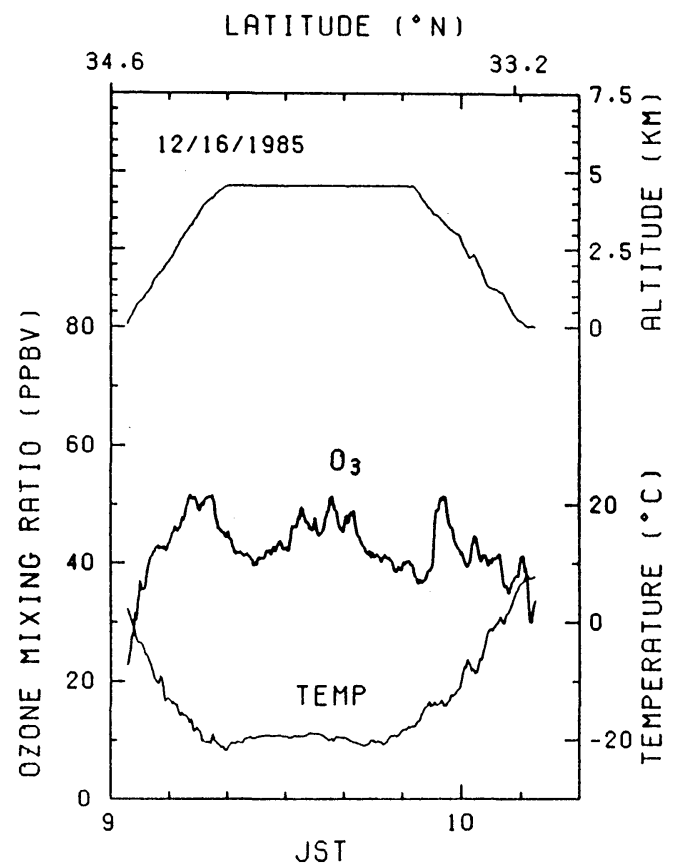

Fig. 7(a). Measured ozone mixing ratio on board the aircraft on December 16, 1985 at latitudes between 33 and $34^{\circ} \mathrm{N}$.

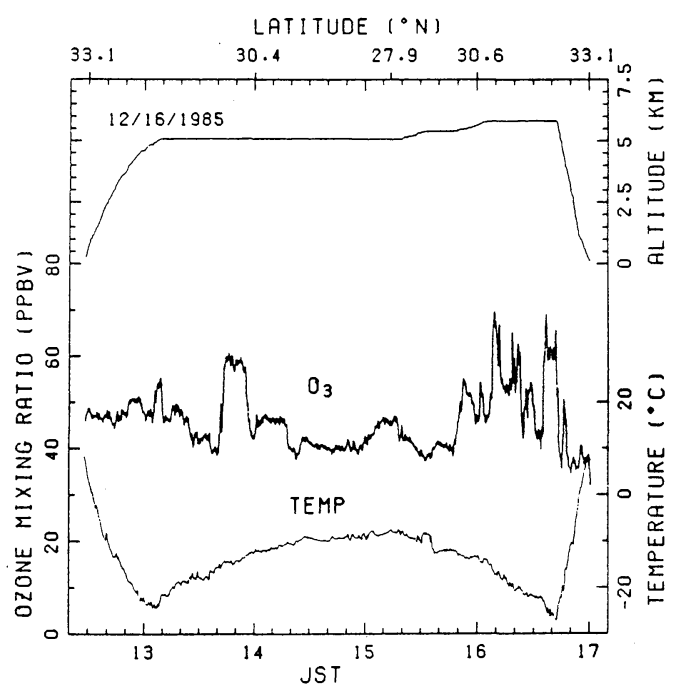

Fig. 7(b). Same as for Fig. 7(a) but for the latitudes between 28 and $33^{\circ} \mathrm{N}$.

computer. The measured ozone concentration together with the temperature is shown in Figures 7(a), (b), and (c). The short term fluctuations of the total and ethylene mass flow rates did not exceed $2 \%$ and the drift of the total mass flow rate was about $2 \%$ throughout the observa-

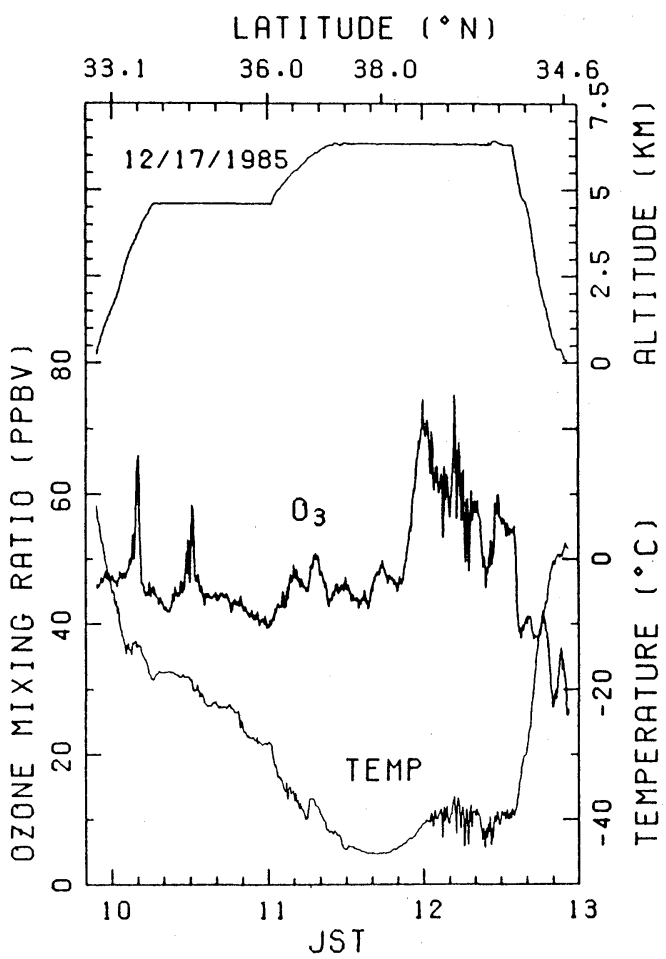

Fig. 7(c). Same as for Fig. 7(a) but for December 17, 1985 and the latitudes between 35 and $38^{\circ} \mathrm{N}$.

tional series. It can be seen from these figures that the measured ozone mixing ratio in the midtroposphere is in the range between 40 and 60 ppbv with a number of small scale structures. Further analysis of this data, together with that of $N O_{x}$ which was measured simultaneously, will be reported elsewhere.

\section{Summary}

A chemiluminescent instrument for groundbased observations of ozone was modified for aircraft observations. A series of detailed test showed that the sample and ethylene mass flow rates need to be controlled precisely in order to maintain constant sensitivity both for groundbased and aircraft observations. The sensitivity changes little between 1000 and $500 \mathrm{mb}$ and the reduction of the sensitivity at pressures lower than $400 \mathrm{mb}$ can be minimized by selecting optimum sample and ethylene flow rates.

The dependence of the output signal on the sample and ethylene flow rates and on the pressure is not identical to that of the calculated total emission rate. This suggests that the spatial 
distribution of the photo-emission in the chamber changes considerably depending on the flow conditions. This is due in part to the slow reaction rate of ethylene and ozone. It is therefore likely that the present design of the chamber is not necessarily the best suited for aircraft observations.

No serious interference from water vapor has been detected. It seems that the chemiluminescent instrument can be more accurate than $U V$ photometers, especially at low ozone mixing ratios. This is mainly due to the relative stability of the zero level and the high signal to noise ratio. In addition, the short "warm up" time required is suited to aircraft observations.

\section{Acknowledgments}

We wish to thank $\mathrm{H}$. Jindo and M. Kanada for their technical assistance during the course of the integration of the instrument. Thanks are due to A. Iwata who supported the data acquisition and reduction for the aircraft observations. This work has been supported financially as part of the Middle Atmosphere Program (MAP) by the Japanese Ministry of Education and the National Institute of Polar Research.

\section{References}

Aimedieu, P. and J. Barat, 1981: Instrument to measure stratospheric ozone with high resolution. Rev. Sci.
Instrum., 52, 432-437.

Finlayson, B.J., J.N. Pitts, Jr. and H. Akimoto, 1972: Production of vibrationally excited $\mathrm{OH}$ in chemiluminescent ozone-olefin reactions. Chem. Phys. Lett., 12, 495-498.

Gregory, G.L., C.H. Hudgins and R.A. Edahl, Jr., 1983a: Laboratory evaluation of an airborne ozone instrument that compensates for altitude/sensitivity effects. Environ. Sci. Technol., 17, 100-103.

- - - and 1983b: Reply to O'Brien et al., 1983. Environ. Sci. Technol., 17, $562-564$.

, S.M. Beck and J.A. Williams, 1984: Measurements of free tropospheric ozone: an aircraft survey from $44^{\circ}$ north to $46^{\circ}$ south latitude. J. Geophys. Res., 89, 9642-9648.

Japar, S.M., C.H. Wu and H. Niki, 1974: Rate constants for the reaction of ozone with olefins in the gas phase. J. Phys. Chem., 78, 2318-2320.

Kondo, Y., W.A. Matthews, A. Iwata, Y. Morita and M. Takagi, 1987: Aircraft measurements of oxides of nitrogen along the eastern rim of the Asian continent: winter observations. J. Atmos. Chem., 5, 3758.

Mehrabzadeh, A.A., R.J. O'Brien and T.M. Hard, 1983: Generalized response of chemiluminescence analyzers. Rev. Sci. Instrum., 54, 1712-1718.

O'Brien, R.J., T.M. Hard and A.A. Mehrabzadeh, 1983: Comment on Gregory et al., 1983. Environ. Sci. Technol., 17, 560-562.

Routhier, F., R. Dennett, D.D. Davis, A. Wartburg, P. Haagenson and A.C. Delany, 1980: Free tropospheric and boundary-layer airborne measurements of ozone over the latitude range of $58^{\circ} \mathrm{S}$ to $70^{\circ} \mathrm{N}$. J. Geophys. Res., 85, 7307-7321.

\title{
航空機観測のための化学螢光法オゾン測定器
}

\author{
近藤 豊・小島 浩 ·鳥山哲司・森田恭弘 ·高木増美 \\ (名古屋大学空電研究所) \\ W. A. Matthews \\ (ニュージーランド科学産業省物理工学研究所) \\ エチレンーオゾンの化学蛍光法によるオゾン測定器を改修して，サンプル空気及びェチレンの流量を外気圧 \\ に無関係に一定に保てるようにした。 \\ この測定器の特性を実験室で詳しく試験した結果以下の事が判明した。 \\ (1) 測定器の感度はサンプル大気の質量流量により大きく変わる。 \\ (2) エチレン質量流量に対する感度依存性はこれに比べかなり小さい。 \\ （3）ゼロレベル及び直線性からのずれから生じる測定誤差は1 ppbvより小さい。 \\ (4) 1000 から $500 \mathrm{mb}$ の間での感度の変化は小さいが， $500 \mathrm{mb}$ 以下では測定した校正值に基づく補正が必 \\ 要となる。その補正は $400 \mathrm{mb}$ では約10\%である。 \\ この測定器を用いて高度 $6 \mathrm{~km}$ をでのオゾンの航空機観測を行った。このとき流量制御系は流量を $3 \%$ の精度 \\ で一定に保った。この観測で得られたオゾン濃度も報告する。
}

